\title{
THE GROUND OWL
}

DOROTHY DURR, Broomhead, Sask.

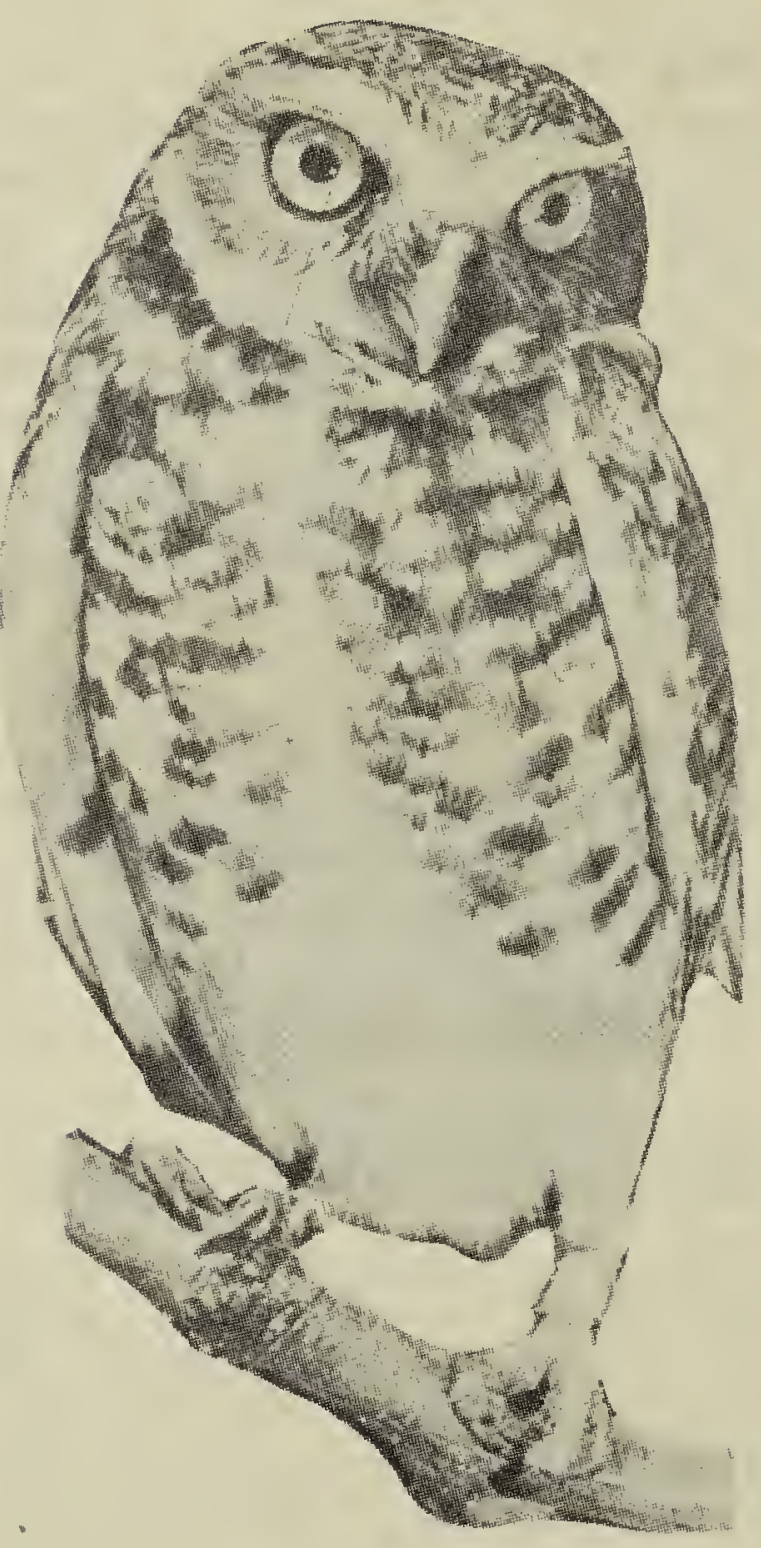

Tavelner calls him the "Burrowing Owl", and other authorities, the "Prairie Owl." However I have chosen to use the name in local use. Here, about eight miles from the International Boundary, we had them in plentiful supply during the dry years. Could be, they prefer cosy dry nests to a "built-in- bath tub" at the base of a badger hole where they usually nest. However, we never lack for at least one family in the higher and drier parts of the pasture.

They are not at all shy, coming at dusk to the house-yard where they search for scraps, picking up small bones which we later found, cleaned, on the nesting knolls. I once found a baby owl outside the hole, and picked him up. The fluffy, round little urchin showing absolutely no fear. Their legs are long and un-owl like, and the large nostril holes on the beak give a peculiar spectaclelike appearance - on the babies in particular. It is quite a sight to see those babies out for an airing in the evening - as many as eight lined in a row.

The following verses illustrate their chief characteristics, and our feeling towards them.

Funny, little Ground Owl

Funny, little round Owl

From the pasture knoll we hear you call

For in the evening cool,

Your children go to school

In scholar's row, eight or nine in all.

Funny, little Ground Owl

Funny, little brown Owl

Sitting on my clothes-line in the dusk

You've been searching for the scraps

Left here by the cats,

Taking all us human folks on trust.

You fumny little cuss

We know you're fond of us,

For you're in our Badger holes each year.

From early spring till fall,

We hear your chirping call,

It isn't summer-time till you appear.

\section{SUMMER RAIN}

The rain clouds loom in the sky tonight,

And clouds in the sky are a welcome sight.

After the days of blistering heat

The tune of a beating rain is sweet.

Tonight the Earth will breathe again,

For tonight will bring the patter of rain.

Rain to freshen the torrid air,

Rain that will make the green life stir,

Rain to moisten the sun-choked flowers.

Thank God for the clouds and the cooling showers.

Eric A. Dowson, Nanaimo, B.C. 